\title{
Hemangioblastoma of the Optic Nerve
}

\author{
-Case Report- \\ Tetsuhiro HIGASHIDA, Katsumi SAKATA, Hiroshi KANNO, Takashi KAWASAKI,
Yutaka TANABE, and Isao YAMAMOTO \\ Department of Neurosurgery, Yokohama City University School of Medicine, \\ Yokohama, Kanagawa

\begin{abstract}
A 64-year-old man presented with a rare sporadic hemangioblastoma arising in the left optic nerve manifesting as left visual disturbance gradually progressive over 5 years. Magnetic resonance imaging revealed a well-enhanced mass in the left optic nerve. Partial resection of the tumor was performed via the frontoorbital approach. The histological diagnosis was optic nerve hemangioblastoma. Hemangioblastoma must be considered in the differential diagnosis of optic nerve tumors even in the absence of other lesions associated with von Hippel-Lindau disease.
\end{abstract}

Key words: hemangioblastoma, optic nerve, von Hippel-Lindau disease

\section{Introduction}

Hemangioblastomas account for $1-2 \%$ of primary tumors of the central nervous system located mainly in the posterior fossa. Over $90 \%$ of hemangioblastomas involve the cerebellum, medulla, or spinal cord, and $40 \%$ of patients have a family history of von Hippel-Lindau disease, which is an autosomal dominant disease with variable manifestations including multiple abdominal visceral cysts and neoplasms such as hemangioblastoma, renal cell carcinoma, and pheochromocytoma. ${ }^{4,9)}$ Retinal hemangioblastomas are often found, but supratentorial hemangioblastomas, especially those arising in the optic nerve, are extremely rare. Here we describe a case of optic nerve hemangioblastoma.

\section{Case Report}

A 64-year-old man presented with a 5-year history of progressive visual disturbance followed by narrowing of the visual field and proptosis of the left eye. During the follow-up period, a left optic nerve mass lesion inside the orbit had gradually grown. Therefore, he was admitted to our hospital for surgical extirpation to confirm the diagnosis. He had no family history of von Hippel-Lindau disease.

Received September 4, 2006; Accepted March 8, 2007
Ophthalmological examination found vision of the left eye could just perceive hand motion and was limited to central vision. The left pupil was dilated without direct light reflex. Non-pulsating proptosis was apparent, but he had no ocular pain or disturbance of extraocular movement.

Magnetic resonance (MR) imaging demonstrated a well-defined solid mass in the left optic nerve inside the orbit appearing as isointense on the $T_{1}$ weighted image and heterogeneously hyperintense on the $\mathrm{T}_{2}$-weighted image (Fig. 1A, B). The left optic nerve beside the mass was remarkably swollen. Several dilated vessels surrounding the tumor were also identified. The mass was homogeneously enhanced with a clear border by gadolinium (Fig. 1C, D). No other intracranial lesions were identified. The preoperative differential diagnosis included optic nerve glioma, optic nerve sheath meningioma, schwannoma, and optic neuritis.

Surgery was performed to obtain the definitive histological diagnosis. The swollen left optic nerve inside the orbit was identified through a left frontoorbital craniotomy. Incision of the optic nerve sheath revealed a red mass (Fig. 2). This mass was not attached to the optic nerve sheath. However, the border between the mass and the optic nerve was not clear, and there were no dilated vessels inside or around the tumor. Frozen section examination of the tumor specimen revealed proliferating cellular lesion, but the pathological diagnosis was not con- 

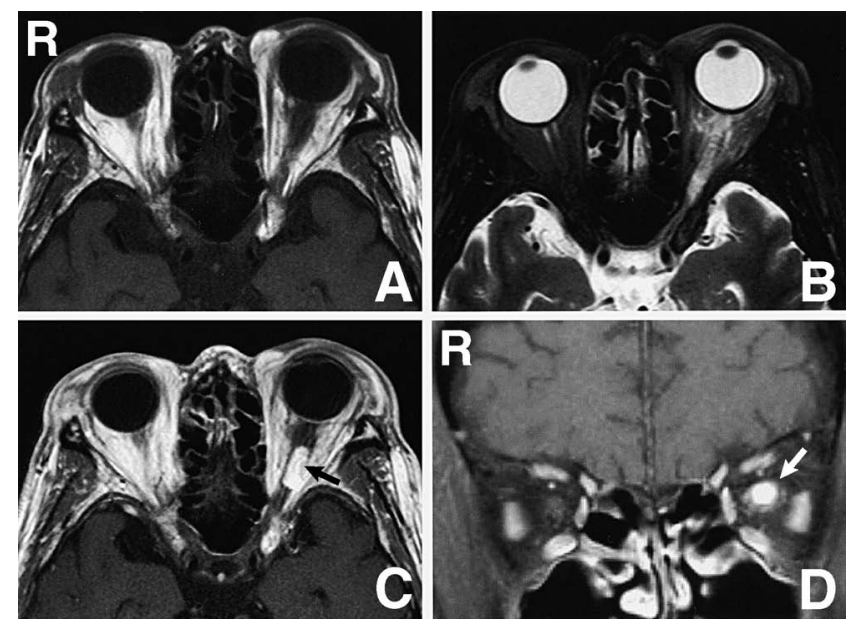

Fig. 1 Magnetic resonance images showing a mass (arrows) in the swollen left optic nerve inside the orbit as isointense on the axial $T_{1}$-weighted image (A), heterogeneously hyperintense on the axial $T_{2}$-weighted image (B), and with homogeneous enhancement on the axial (C) and coronal (D) $\mathrm{T}_{1}$-weighted images with gadolinium.

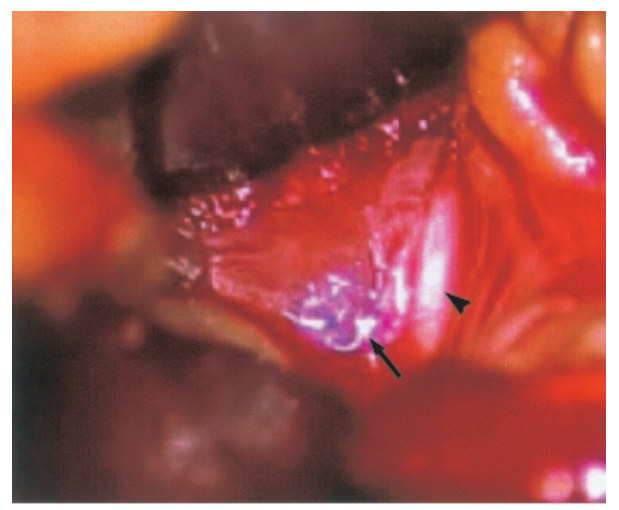

Fig. 2 Intraoperative photograph demonstrating the tumor (arrow) located in the left optic nerve. Arrowhead indicates optic nerve sheath.

firmed during the operation. Partial resection of the tumor was performed, because the tumor was too hemorrhagic to be removed totally without optic nerve injury.

No remarkable neurological change including vision occurred during the postoperative course. Histological examination of the specimen revealed the typical features of hemangioblastoma, including high vascularization, proliferation of stromal cells containing lipid-rich vacuolated cytoplasm, and reticulin framework (Fig. 3A, B). No spindle-shaped

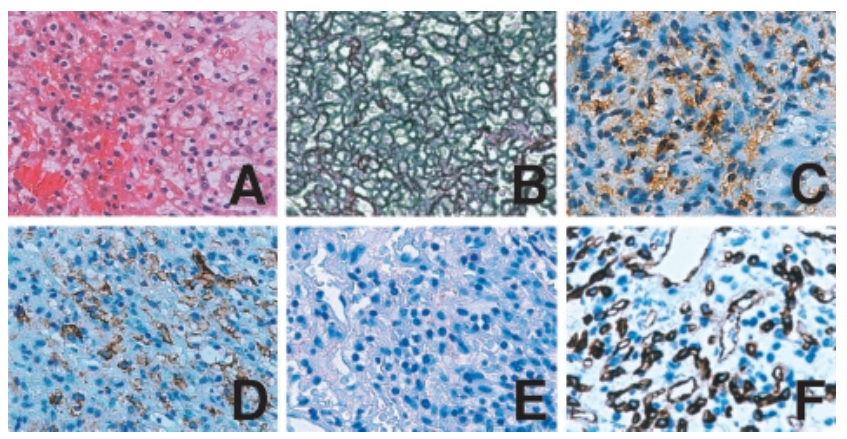

Fig. 3 Photomicrographs of the optic nerve mass showing a highly vascular tumor (A, hematoxylin and eosin stain) with reticulin framework (B, reticulin silver stain) and proliferation of vacuolated foamy cells (A), with moderately positive immunoreaction for S-100 protein (C) and glial fibrillary acidic protein (D), but negative reaction for epithelial membrane antigen in the stromal cells (E), and positive reaction for CD34 in the capillary endothelial cells, but not in the stromal cells (F). Original magnification $\times 400$.

cells or cells with hair-like processes were identified, which excluded glioma and schwannoma. Immunohistochemical analysis showed that the stromal cells were moderately positive for S-100 protein and glial fibrillary acidic protein (GFAP), and negative for epithelial membrane antigen (EMA) (Fig. 3C-E). Immunoreactivity to CD34 was detected in the proliferating capillary endothelial cells, but not in the stromal cells (Fig. 3F). These findings excluded meningioma and supported the diagnosis of hemangioblastoma. No other lesion was identified except for an asymptomatic solitary kidney cyst. Therefore, the final diagnosis was sporadic optic nerve hemangioblastoma.

\section{Discussion}

Preoperative diagnosis of optic nerve hemangioblastoma is difficult in patients without lesions associated with von Hippel-Lindau disease. The differential diagnosis includes glioma, meningioma, schwannoma, and retrobulbar neuritis. MR imaging shows that glioma and neuritis are usually less enhanced by gadolinium than hemangioblastoma. Meningioma is well enhanced, but arises from the optic nerve sheath which can be distinguished from the optic nerve on the coronal section of MR imaging. However, these tumors are sometimes difficult to differentiate with MR images and clinical infor- 
Table 1 Summary of patients with optic nerve hemangioblastoma

\begin{tabular}{|c|c|c|c|c|c|c|}
\hline Author (Year) & Age (yrs)/Sex & Side & Location & Gross appearance & Surgery & VHL disease \\
\hline Schneider $(1942)^{15)}$ & $26 / F$ & lt & IO & solid & yes & no \\
\hline Stefani and Rothemund (1974) & $43 / \mathrm{M}$ & $\mathrm{rt}$ & IC & solid & no & no \\
\hline Lauten et al. $(1981)^{9)}$ & $15 / \mathrm{M}$ & lt & IO, IC & solid & yes & no \\
\hline Eckstein et al. $(1981)^{2)}$ & $39 / F$ & lt & $\mathrm{IO}$ & solid & yes & no \\
\hline In et al. $(1982)^{5)}$ & $23 / \mathrm{F}$ & lt & IO & solid & yes & yes \\
\hline Tanaka et al. $(1984)^{17)}$ & $37 / \mathrm{M}$ & $\mathrm{rt}$ & IO & solid & yes & yes \\
\hline Nerad et al. $(1988)^{12)}$ & $18 / \mathrm{F}$ & lt & IO & solid & yes & yes \\
\hline Hotta et al. $(1989)^{4)}$ & $36 / \mathrm{M}$ & $\mathrm{rt}$ & IO & solid & yes & yes \\
\hline Ginzburg et al. (1992) & $44 / \mathrm{M}$ & bil & IC & solid & yes & yes \\
\hline Rubio et al. $(1994)^{14)}$ & $43 / \mathrm{F}$ & $\mathrm{rt}$ & IO, IC & solid & yes & yes \\
\hline Miyagami et al. $(1994)^{11)}$ & $26 / F$ & $\mathrm{rt}$ & IC & solid & yes & yes \\
\hline Kerr et al. $(1995)^{8)}$ & $27 / F$ & $\mathrm{rt}$ & $\mathrm{IO}, \mathrm{IC}$ & solid & yes & yes \\
\hline Raila et al. (1997) ${ }^{13)}$ & $30 / \mathrm{F}$ & lt & IC & solid & yes & yes \\
\hline Kato et al. (2004) $)^{7)}$ & $29 / \mathrm{M}$ & $\mathrm{rt}$ & $\mathrm{IO}, \mathrm{IC}$ & solid & yes & no \\
\hline Present case & $64 / \mathrm{M}$ & lt & $\mathrm{IO}$ & solid & yes & no \\
\hline
\end{tabular}

IC: intracranial, IO: intraorbital, VHL: von Hippel-Lindau.

mation. Angiography can be useful because gliomas, schwannomas, and neuritis are usually hypovascular, whereas hemangioblastoma is exclusively hypervascular. Optic nerve hemangioblastoma is mainly supplied by the ophthalmic artery and drained by dilated veins around the tumor. . $^{2,4,7,9,11,13,17)}$ These findings suggest that hemangioblastoma arises from the optic nerve tissue rather than the optic nerve sheath, ${ }^{3,5,12)}$ and may be useful to differentiate hemangioblastoma from meningioma and schwannoma.

Histological examination shows that optic nerve hemangioblastoma usually does not have a capsule, ${ }^{9,16,17)}$ in contrast to meningioma. Immunohistochemical analysis reveals negative immunoreactivity of stromal cells to EMA, also different from meningioma. Other immunohistochemical findings are still controversial. Immunoreactivity of stromal cells to S-100 protein and GFAP is sometimes positive. ${ }^{6)}$ Immunoreactivity to CD34 is usually negative in stromal cells, but positive in capillary endothelial cells and angiogenic precursor cells around vessels. ${ }^{1)}$

Only 15 cases of optic nerve hemangioblastoma including the present case have been reported (Table 1). ${ }^{2-5,7-9,11-17)}$ Two controversial cases were excluded because the diagnosis was unclear. ${ }^{8,13)}$ The seven male and eight female patients were aged from 15 to 64 years (median 30 years, mean 33.3 years). Nine cases were associated with von HippelLindau disease. Six cases including our case were sporadic. All tumors were located in the prechiasmal retrobulbar optic nerve, only within the orbit in seven cases, outside the orbit in four cases, and in both portions in four cases. One patient had bilateral lesions. Visual disturbance was the initial symptom in 12 patients. Other common symptoms included visual field defect, headache, or pressure-like feeling of the eye. Proptosis was detected in all patients with intraorbital tumor. As many as $60 \%$ to $80 \%$ of hemangioblastomas are cystic, ${ }^{\text {9) }}$ but all optic nerve hemangioblastomas were solid.

The origin of hemangioblastomas is controversial, but may involve the leptomeningeal vasculature or the nerve tissue. ${ }^{2,3,12)}$ However, the tumors are usually well demarcated from the nerve tissue..$^{2,3,8,9,12-14)}$ These findings indicate the potential resectability of the tumor. Surgery was performed in all cases except one. ${ }^{16)}$ The visual function was preserved after surgery in several patients., ${ }^{3,8,13)}$ All patients with optic nerve hemangioblastoma suffer progressive visual disturbance leading to blindness, so total removal in the early stage is recommended. ${ }^{8,10,13)}$ Prompt recognition of this rare entity is important because early diagnosis and treatment can preserve the vision.

\section{References}

1) Chan CC, Chew EY, Shen D, Hackett J, Zhuang Z: Expression of stem cells markers in ocular hemangioblastoma associated with von Hippel-Lindau (VHL) disease. Mol Vis 11: 697-704, 2005

2) Eckstein RP, Wills EJ, Segelov JN: Haemangioblastoma of the optic nerve. Case report with study by light and electron microscopy. Pathology 13: 357-364, 1981

3) Ginzburg BM, Montanera WJ, Tyndel FJ, Griesman JA, McLennan MK, Ter Brugge KG, Willinsky RA: 
Diagnosis of von Hippel-Lindau disease in a patient with blindness resulting from bilateral optic nerve hemangioblastomas. AJR Am J Roentgenol 159: 403-405, 1992

4) Hotta H, Uede T, Morimoto S, Tanabe S, Hashi K, Takeda M: [Optic nerve hemangioblastoma. Case report]. Neurol Med Chir (Tokyo) 29: 948-952, 1989 (Jpn, with Eng abstract)

5) In S, Miyagi J, Kojho N, Kuramoto S, Uehara M: Intraorbital optic nerve hemangioblastoma with von Hippel-Lindau disease. Case report. J Neurosurg 56: 426-429, 1982

6) Ishizawa K, Komori T, Hirose T: Stromal cells in hemangioblastoma: neuroectodermal differentiation and morphological similarities to ependymoma. Pathol Int 55: 377-385, 2005

7) Kato K, Utsunomiya A, Uenohara H, Suzuki S, Takahashi N, Suzuki H, Nishino A, Nishimura S, Sakurai Y: [Hemangioblastoma of the optic nerve growing like a dumbbell through the optic canal: case report]. No To Shinkei 56: 711-716, 2004 (Jpn, with Eng abstract)

8) Kerr DJ, Scheithauer BW, Miller GM, Ebersold MJ, McPhee TJ: Hemangioblastoma of the optic nerve: case report. Neurosurgery 36: 573-581, 1995

9) Lauten GJ, Eatherly JB, Ramirez A: Hemangioblastoma of the optic nerve: radiographic and pathologic features. AJNR Am J Neuroradiol 2: 96-99, 1981

10) Miller NR: Primary tumours of the optic nerve and its sheath. Eye 18: 1026-1037, 2004

11) Miyagami M, Miyagi A, Kido G, Satoh K, Tsubokawa $\mathrm{T}$ : [The two familial occurrence of von Hippel-
Lindau disease]. No To Shinkei 46: 683-689, 1994 (Jpn, with Eng abstract)

12) Nerad JA, Kersten RC, Anderson RL: Hemangioblastoma of the optic nerve. Report of a case and review of literature. Ophthalmology 95: 398-402, 1988

13) Raila FA, Zimmerman J, Azordegan P, Fratkin J, Parent AD: Successful surgical removal of an asymptomatic optic nerve hemangioblastoma in von Hippel-Lindau disease. J Neuroimaging 7: 48-50, 1997

14) Rubio A, Meyers SP, Powers JM, Nelson CN, de Papp EW: Hemangioblastoma of the optic nerve. Hum Pathol 25: 1249-1251, 1994

15) Schneider R: Angioretikulom des Sehnerven. Graefes Arch Clin Exp Ophthalmol 145: 163-178, 1942, cited in ref. 8)

16) Stefani FH, Rothemund E: Intracranial optic nerve angioblastoma. Br J Ophthalmol 58: 823-827, 1974

17) Tanaka E, Kimura C, Inoue H, Otani M, Kigasawa K, Yamazaki K, Shiga H: [A case of intraorbital hemangioblastoma of the optic nerve]. Nihon Ganka Kiyo 35: 1390-1395, 1984 (Jpn, with Eng abstract)

Address reprint requests to: Tetsuhiro Higashida, M.D., Department of Neurosurgery, Yokohama City University School of Medicine, 3-9 Fukuura, Kanazawa-ku, Yokohama 236-0004, Japan. e-mail: t056042a@yokohama-cu.ac.jp 